\title{
Modelling the effect of an improved trace and isolate system in the wake of a highly transmissible Covid-19 variant with potential vaccine escape
}

\section{Author}

Cam Bowie (0000-0002-6956-3691)

Lowani, Lyme Road, Axminster, EX13 5BL, UK

Retired Director of Public Health, Somerset, UK

Correspondence to: Cam Bowie cam.bowie1@gmail.com

\section{Abstract}

- Objective - How helpful would a properly functioning find, test, trace, isolate and support (FT'TIS) system be now in the UK with new Covid-19 infections at a low level and half the adult population immunised but with a highly transmissible variant becoming predominant?

- Design - a dynamic causal model of Covid-19 supplied with the latest available empirical data is used to assess the impact of a new highly transmissible variant.

- Setting - the United Kingdom.

- Participants - a population based study.

- Interventions - scenarios are used to explore a Covid-19 transmission rate 50\% more and twice the current rate with or without a more effective FT'TIS system.

- Main outcome measures - incidence, death rate and reproductive ratio

- Results - a small short third wave of infections occurs which does not occur if FTTTS effectiveness is improved from $25 \%$ to $30 \%$.

- Conclusion - a modest improvement in FT'TIS would prevent a third wave caused by a highly transmissible virus. 


\section{Introduction}

The failure of the UK government to establish an effective find, test, trace, isolate and support (F'TTIS) system since the start of the Covid-19 pandemic is accepted by many, including the Public Accounts Select Committee of the UK parliament. Its report included a searingly critical headline "Unimaginable cost of Test \& Trace failed to deliver the central promise of averting another lockdown" (1). A traditional public health approach at the local level was recommended soon after the start of the first outbreak in the UK when it was apparent that the Department of Health were set on a centralised approach, seemingly without an exit strategy (2). The government was ignoring the successful control from Asia requiring only limited lockdown (3).

But how helpful would a properly functioning F'TTIS system be now with new Covid-19 infections at a low level and half the adult population immunised? Is it too late to set one up? A dynamic causal model of Covid19 can be used to answer this question (4).

\section{Methods}

\section{The Dynamic Causal Model}

An advantage of dynamic causal models (DCMs) is that the models are designed to continually assimilate data and modify model parameters, such as transmissibility of the virus, changes in social distancing and vaccine coverage- to accommodate changes in population dynamics and virus behaviour. The latest model ( $1^{\text {st }}$ June 2021) can be used to explore the effect of increased virus transmissibility and the potential benefit of a successful F'T'TIS scheme.

The model is fully described [5] and a weekly dashboard provides up-to-date estimates and projections (6). The software is freely available. The following section describes the features of the model for non-modelling experts. The model includes all the standard SEIR (susceptible, exposed, infected, removed) features of the commonly used models of infectious disease but in addition incorporates the interactions between the different variables. For example people are more likely to stay at home if the prevalence is high or if they have not been immunised. These dependencies are estimated and only retained if they improve the ability of the model to account for the data. Having optimised the model and model parameters, one can then proceed with scenario modelling to evaluate the effect of interventions; e.g. the influence of an enhanced F'T'TIS system on the epidemic.

Standard SEIR models depend on the choice of parameters, some of which are unknown empirically and have to be guessed. Dynamic causal modelling is, by comparison, relatively assumption free. However, one has to specify prior ranges for parameters (just like for SEIR models) but the DCM adjusts the parameters to fit the data in the most efficient and parsimonious way possible. Not only does the model provide estimates and projections of variables such as the death rate, the effective reproductive number, incidence and prevalence but it also estimates of transmissibility, susceptibility, latent resistance, herd immunity, expected social distancing behaviour and vaccine efficacy.

Two features provide insight into the way the model describes the interaction of the population and Covid-19. The first is the accuracy of the model in modelling the past stages of the epidemic. The second is the ability of the model to predict what will happen if we carry on as we have so far. The model can even predict based on past performance when social distancing will be relaxed before or on account of 10 Downing Street announcements!

\section{Setting up scenarios to assess the effect of effective tracing}

The initial model parameters can be specified to reflect the most recent empirical evidence concerning isolation behaviour and the current effectiveness of the tracing system through NHS Test \& Trace, Public Health England and local efforts. The most recent CORSAIR study finds only $51 \%$ of people complete isolation after symptoms or being identified as a contact (7). The ten-day isolation period was reduced to 6.7 days to accommodate this (in the model symptoms are estimated to last 3.4 days, the remaining isolation period of 6.6 days is therefore reduced by $51 \%$ to 3.3 days, which when added to 3.4 days gives 6.7 days. A recent PHE inhouse estimate of tracing efficacy finds about $25 \%$ of contacts are traced in time to reduce asymptomatic spread of infection (8). This level of tracing efficacy is used as the baseline for our subsequent scenario modelling.

The first set of scenarios assume that a variant comes to dominate the epidemic and increases transmissibility of the existing range of variants by $50 \%$ starting on $1^{\text {st }}$ June 2021. A second set of scenarios assume the variant has 
medRxiv preprint doi: https://doi.org/10.1101/2021.06.07.21258451; this version posted June 10, 2021. The copyright holder for this preprint (which was not certified by peer review) is the author/funder, who has granted medRxiv a license to display the preprint in perpetuity.

It is made available under a CC-BY 4.0 International license.

twice the transmissibility of the current range of variants. FTTIS performance is improved to provide $30 \%$ success.

\section{Results}

\section{Baseline}

The baseline results—prior to a new variant—can be found in the Dynamic Causal modelling dashboard of $24^{\text {th }}$ May 2021 (https://www.fil.ion.ucl.ac.uk/spm/covid-19/dashboard/). No third wave occurs this year (Figure 1). Full results are found on the dashboard (which provides access to past reports).

Figure 1 - incidence rate of Covid-19 infection in UK January 2020 to December 2021 modelled on $24^{\text {th }}$ May 2021

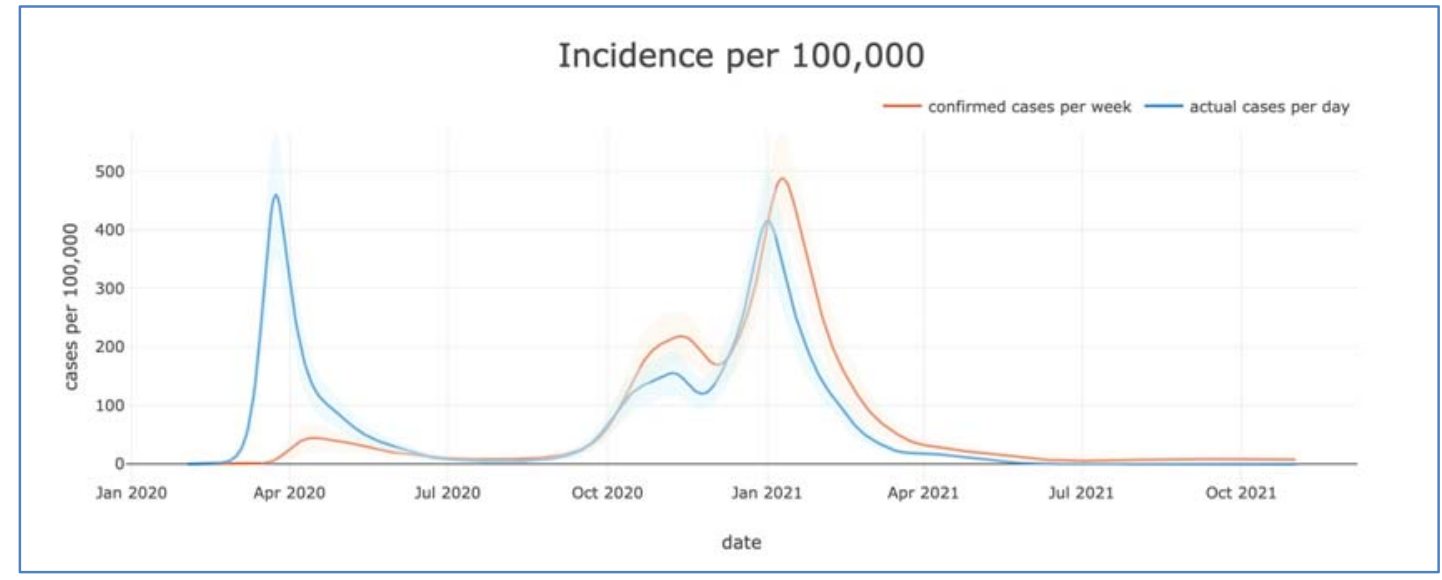

\section{Modifications to model parameters related to FTTIS}

The model here used parameters based on data to 1 st June 2021 and assumes FTTIS is $25 \%$ (not $4 \%$ ) effective and the average isolation period is 6.5 not 10 days. The revised figure shows a slight but transitory increase in incidence over the next few weeks (Figure 2).

Figure 2 - incidence rate of covid-19 infection in UK January 2020 to January 2021 modelled on $1^{\text {st }}$ June

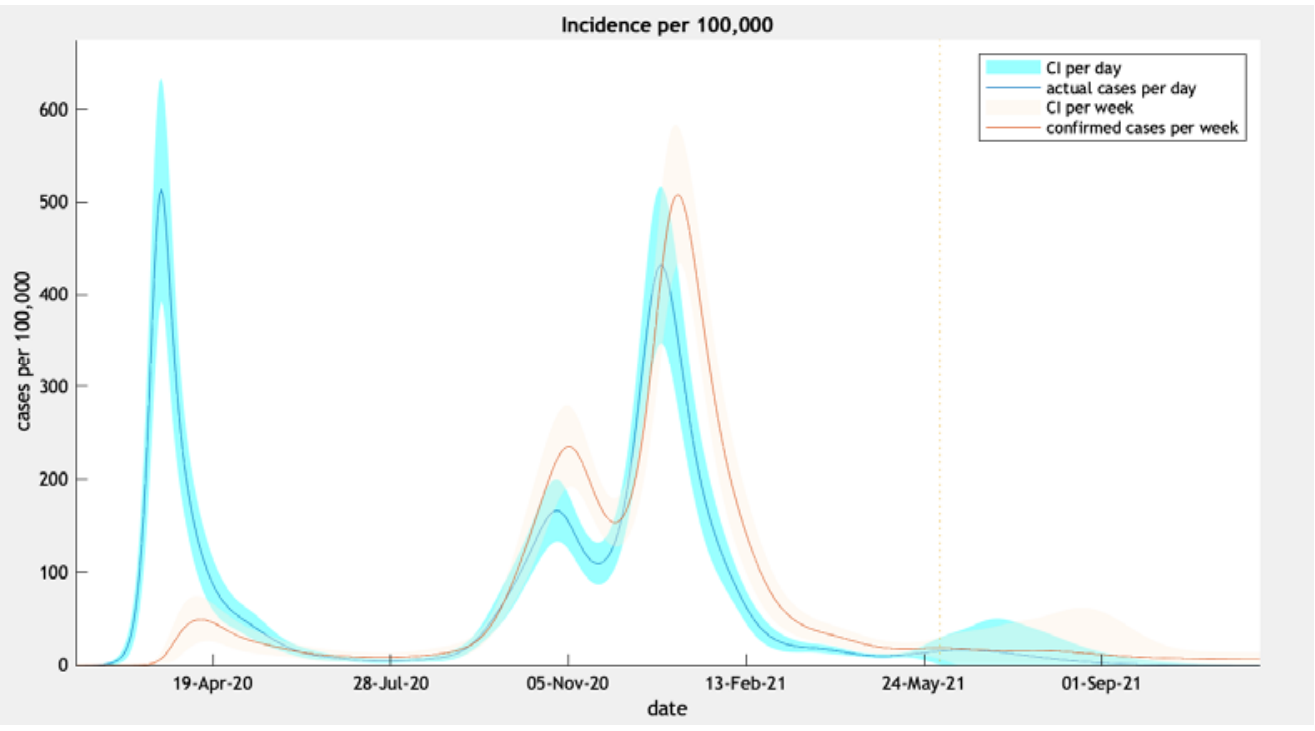

\section{Scenario with new variant which is $50 \%$ more transmissible}

Three scenarios were then considered. The first (NPI1) is the baseline. The second (NPI2) increases transmission by 50\% mimicking a new variant such as the Delta (first identified in India) variant - B1.617.2. The third scenario (NPI3) responds to the new variant by increasing the efficacy of FT'TIS by $20 \%$ (from $25 \%$ to $30 \%$ ). The charts show the forecasts based upon posterior predictive estimates under the three scenarios.

$\mathbf{1}^{\text {st }}$ set of scenario projections - NPI $1=$ no new variant; NPI $=$ New variant $50 \%$ more transmissible; NPI3 $=$ New variant plus improved F'T'TIS by $20 \%$ 
medRxiv preprint dol: https://doi.org/10.1101/2021.06.07.21258451; this version posted June 10, 2021. The copyright holder for this preprint (which was not certified by peer review) is the author/funder, who has granted medRxiv a license to display the preprint in perpetuity.

It is made available under a CC-BY 4.0 International license.

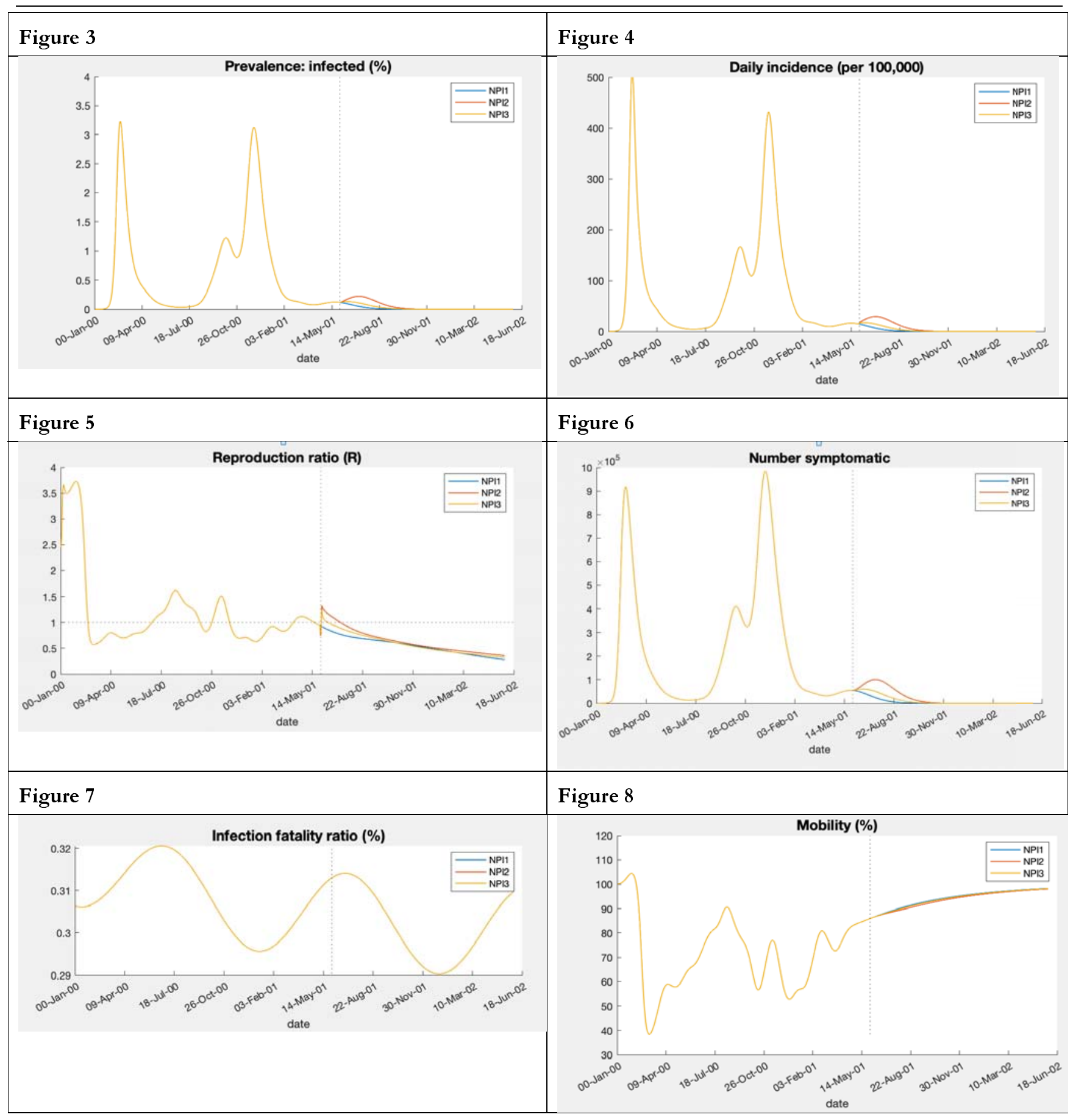

$2^{\text {nd }}$ set of scenario projections - DPI $=$ no new variant; NPI2 $=$ New variant twice as transmissible; NPI3 $=$ New variant plus improved F'T'TIS by $20 \%$

Figure 9

Figure 10 
medRxiv preprint doi: https://doi.org/10.1101/2021.06.07.21258451; this version posted June 10, 2021. The copyright holder for this preprint (which was not certified by peer review) is the author/funder, who has granted medRxiv a license to display the preprint in perpetuity. It is made available under a CC-BY 4.0 International license.

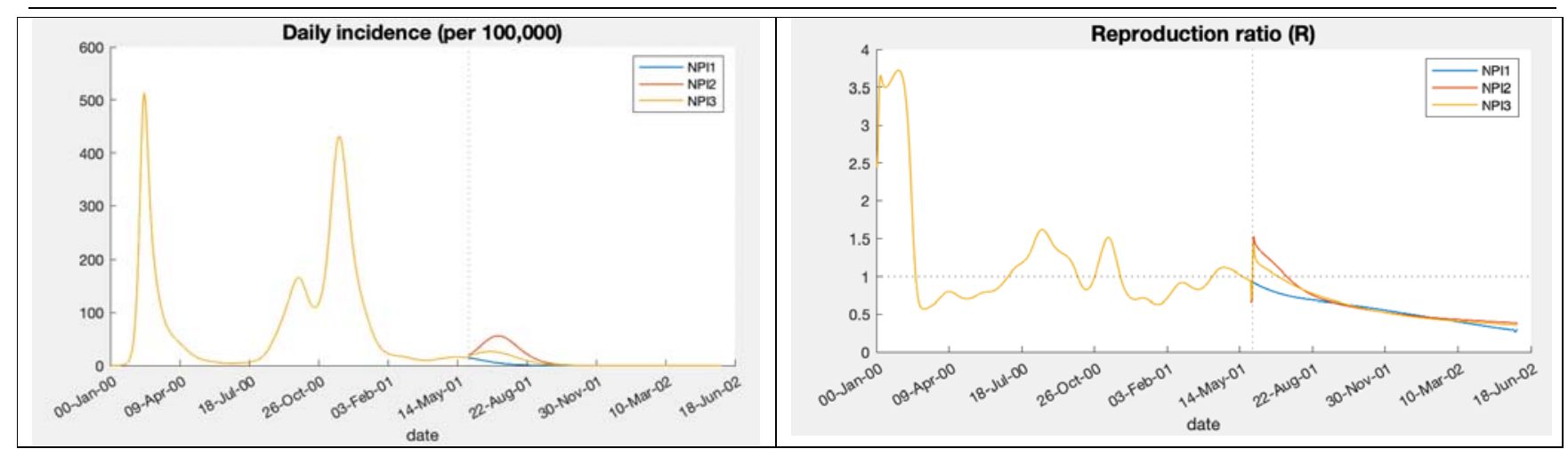

\section{Baseline estimate - Attack rate, immunity and vaccine efficacy as estimated on 19th April and ${ }^{\text {st }}$ June}

Figure 11 - Vaccine efficacy estimated on 19th April 2021

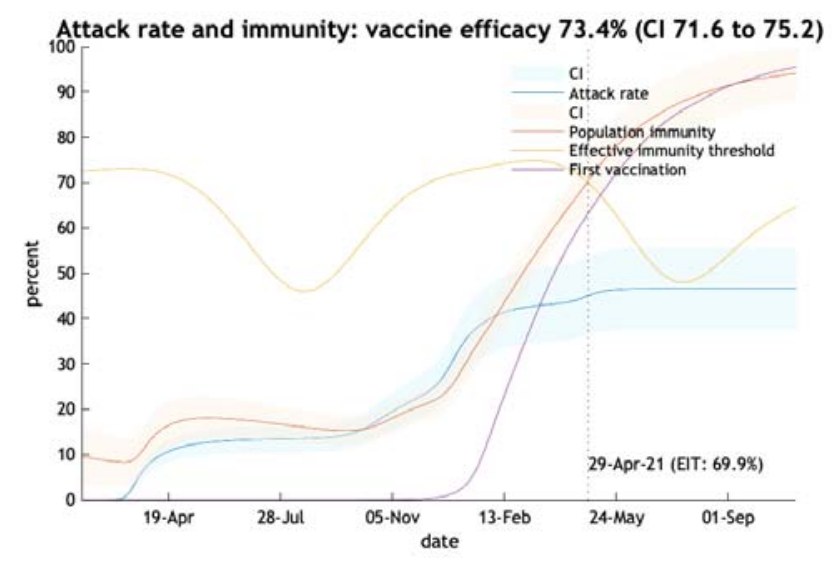

Figure 12 - Vaccine efficacy estimated on 1st June 2021

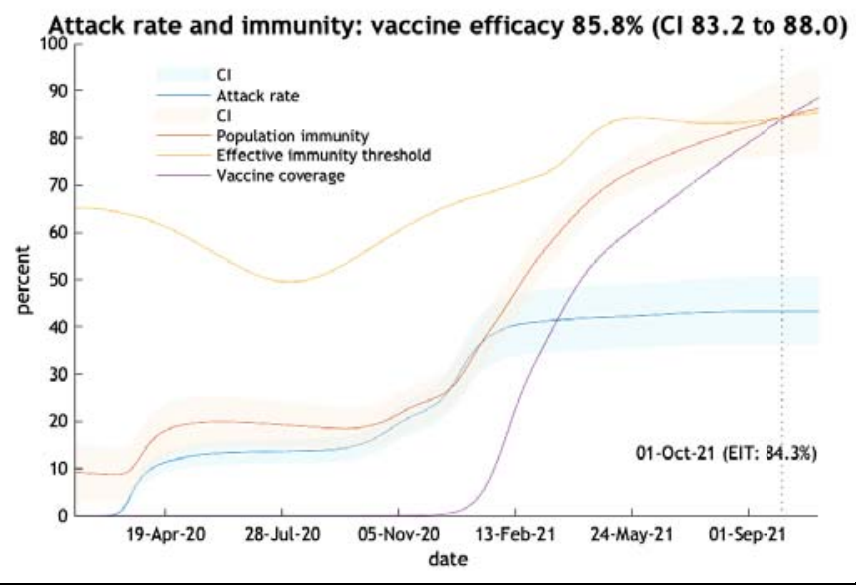

The key findings are as follows:

1. The rise in cases and subsequent deaths is limited despite the $50 \%$ increase in transmissibility and lasts only three months (Figure 3 and Figure 4).

2. A modest improvement in FTTIS from $25 \%$ to $30 \%$ has the effect of reducing the rise in cases and deaths. Further improvements in F'T"TIS would eliminate the increase in cases.

3. The reproduction ratio goes above one with the new variant but rapidly falls below one and more so with improved FT'TIS (Figure 5).

4. The infection fatality ratio drops off in all scenarios as admissions do not embarrass ITUs and improved treatments and vaccine coverage take effect (Figure 7).

5. Mobility is similar in each scenario and increases over time (Figure 8).

6. A variant with double the current transmissibility produces a larger wave than with a $50 \%$ increase in transmissibility, but the wave is limited and short lived without the need for lockdown (Figure 9). This is despite a reproductive ratio above 1 for the month of June (Figure 10).

7. Vaccine efficacy is estimated to remain high at this early stage of a new variant. However despite high vaccine roll out the date of achieving herd immunity has moved from $29^{\text {th }}$ A pril to $1^{\text {st }}$ October (Figure 11 and Figure 12).

\section{Discussion}

Despite easing of social distancing restrictions, new variants with $50 \%$ more transmissibility are unlikely to produce a large third wave and a new lockdown. But this prediction is at risk if the new variant is found to be resistant to vaccine induced immunity. The value of improving FTTIS is clear: a small improvement in tracing and isolating asymptomatic cases will have a tangible effect on epidemic control. Improved tracing efficacy 
requires faster identification of contacts through faster testing and feeding back results, local tracing by door to door tracers and support of those required to isolate (9).

One of the values of using dynamic causal modelling is the ability to test pre-conceived ideas and allow the epidemic itself to estimate the parameters of the epidemic as it unfolds. The method also offers a factorial view of the epidemic rather than a unidimensional view as provided by standard SEIR models. DCM allows an interplay between the various effects of behaviour, epidemiology and seasonality that are key to the control of the epidemic. For instance the non-mandatory response to an increase in Covid-19 prevalence is one of the factors used in the model. This provides insight into how individuals will respond to surges in prevalencebased upon responses to previous fluctuations.

The limitations of the approach are significant. While the model is able to factor in past behaviour it cannot predict the biological characteristics of a new Covid-19 variant. But based on the performance of the virus in recent weeks it seems that the level of vaccine induced immunity plus the immunity produced by past infection will place limits on the next wave of infections.

The role of FT'TIS is interesting. A marginal improvement in efficacy at this stage in the epidemic can have a valuable impact on the spread of the virus.

Vaccine efficacy as modelled here but also in real life changes all the time - with seasonality, waning immunity, level of vaccine coverage, past infections and new variant escape. The model predicts an efficacy of $86 \%$ at the moment. But we do not know the properties of the Indian variant as it becomes predominant in the UK. IHME offers an estimate for AstraZeneca of 35\% efficacy at preventing disease and $32 \%$ efficacy at preventing infection by B.1.617 and for Pfizer/BioNTech of $86 \%$ efficacy at preventing disease and $82 \%$ efficacy at preventing infection by B.1.617 (10). This can be compared to the latest Public Health England (PHE) estimates for Pfizer/BioNTech of $88 \%$ and for AstraZeneca of $60 \%$ at preventing symptomatic infection by B.1.617.2 after two doses (11). Time will tell if vaccine efficacy remains as high as current estimates suggest.

\section{Conclusion}

The new B.1.617.2 variant is clearly more infectious than previous ones circulating in the United Kingdom, but its transmission characteristics are not known. One of our scenarios models a $50 \%$ increase in transmission of currently circulating variants. A large third wave is not predicted. A modest improvement in FT'TIS would prevent any wave at all. If this or another variant is more able to escape the current level of herd immunity a third wave is more likely. It is not too late to seek a modest improvement in tracing which would counter this danger.

\section{References}

1. Parliamentary Public Accounts Select Committee. "Unimaginable" cost of Test \& Trace failed to deliver central promise of averting another lockdown - Committees - UK Parliament [nternet]. 2021 [cited 2021 May 24]. Available from: https://committees.parliament.uk/committee/127/public-accounts-committee/news/150988/unimaginablecost-of-test-trace-failed-to-deliver-central-promise-of-averting-another-lockdown/

2. Bowie C, Hill T. Exit strategy to control covid-19 and relaunch the economy. BMJ. 2020 May 11;369:m1851.

3. Cam Bowie. Eating humble pie over Covid 19 control failures - Briefings For Britain [Internet]. 2020 [cited 2021 May 24]. Available from: https://briefingsforbritain.co.uk/eating-humble-pie-over-covid-19-control-failures/

4. Friston KJ, Flandin G, Razi A. Dynamic causal modelling of mitigated epidemiological outcomes. arXiv:201112400 [physics, q-bio] [Internet]. 2020 Nov 24 [cited 2021 Apr 17]; Available from: http://arxiv.org/abs/2011.12400

5. Friston. Dynamic causal modelling of COVID-19 | Wellcome Open Research [Internet]. [cited 2021 Apr 12]. Available from: https://wellcomeopenresearch.org/articles/5-89

6. Karl Friston. Dynamic Causal Modelling of COVID-19 [Internet]. [cited 2021 May 24]. Available from: https://www.fil.ion.ucl.ac.uk/spm/covid-19/

7. Smith LE, Potts HWW, Amlôt R, Fear NT, Michie S, Rubin GJ. Adherence to the test, trace, and isolate system in the UK: results from 37 nationally representative surveys. BMJ. 2021 Mar 31;372:n608. 
medRxiv preprint doi: https://doi.org/10.1101/2021.06.07.21258451; this version posted June 10, 2021. The copyright holder for this preprint (which was not certified by peer review) is the author/funder, who has granted medRxiv a license to display the preprint in perpetuity.

It is made available under a CC-BY 4.0 International license.

8. C Bowie. Metric to measure contact tracing performance v4.docx. PHE; 2021.

9. Independent SAGE. Supported-isolation-final-180321.pdf [Internet]. [cited 2021 Jun 5]. Available from: https: //www.independentsage.org/wp-content/uploads/2021/03/Supported-isolation-final-180321.pdf

10. IHME. 95_briefing_United_Kingdom_16.pdf [Internet]. [cited 2021 Jun 5]. Available from: http://www.healthdata.org/sites/default/files/files/Projects/COVID/2021/95_briefing_United_Kingdom_16.pdf

11. Bernal JL, Andrews N, Gower C, Gallagher E, Simmons R, Thelwall S, et al. Effectiveness of COVID-19 vaccines against the B.1.617.2 variant. medRxiv. 2021 May 24;2021.05.22.21257658.

\section{Data availability}

The DCM model and data used is freely available from https://www.fil.ion.ucl.ac.uk/spm/covid-19/. The model used to construct the scenarios is available from the author. 